\title{
In Vitro Function of Cyst Epithelium from Human Polycystic Kidney
}

Ronald D. Perrone

Renal Division, Department of Medicine, Tufts-New England Medical Center, Boston, Massachusetts 02111

\begin{abstract}
It is thought that cysts in polycystic kidneys originate from nephron segments and function in a manner similar to the segment of origin. The indirect evidence for this derives from studies of microanatomy and cyst fluid composition. Cysts with low $\mathrm{Na}^{+}$ have been classified as distal, whereas cysts with high $\mathrm{Na}^{+}$have been classified as proximal. In order to directly determine the transport characteristics of cyst epithelium, cysts from a human polycystic kidney were studied in vitro using Ussing chamber techniques. Composition of cyst fluid was determined in parallel with these studies.

Cysts with low $\mathrm{Na}^{+}$(gradient cysts) demonstrate characteristics consistent with distal nephron origin including elevated potential difference $(P D)$, short-circuit current $\left(I_{s c}\right)$, and low conductance. $P D$ and $I_{\mathrm{ac}}$ of gradient cysts were amiloride sensitive. Nongradient cysts, however, require additional characterization. At least two types of nongradient cysts were identified, one with characteristics consistent with proximal nephron origin and another apparently without function.

These studies are the first direct evidence for active transport of cysts from human polycystic kidney and provide strong evidence to support the concept that cysts function in the same manner as the nephron segment of origin.
\end{abstract}

\section{Introduction}

Human adult polycystic kidney disease is a hereditary disorder characterized by progressive renal enlargement due to accumulation of fluid in large numbers of cysts scattered throughout the renal parenchyma. The cysts in this disorder are thought to derive from renal tubular segments $(1,2)$. This concept originated from studies of cyst microanatomy (3-5) and from indirect examination of cyst function. Multiple studies of cyst fluid composition have described two populations of cysts, based on the cyst fluid sodium concentration (6-8). Cysts with a low sodium concentration, thereby defined as maintaining a steep gradient between cyst fluid and plasma sodium, have been classified as of distal origin. Cysts with a sodium concentration not greatly different from the plasma, and thus, no sodium gradient, have been classified as proximal. This characterization was further

This work was presented in preliminary form at the National Meeting of the American Federation for Clinical Research, 1985, and has been published in abstract form (1985. Clin. Res. 33:495A).

Address reprint requests to Dr. Perrone, Box 317, Renal Division.

Received for publication 18 June 1985.

J. Clin. Invest.

(c) The American Society for Clinical Investigation, Inc.

$0021-9738 / 85 / 10 / 1688 / 04 \$ 1.00$

Volume 76, October 1985, 1688-1691 supported by ultrastructural examination of cyst epithelium. Cuppage and coworkers (7) demonstrated that cysts with a low sodium concentration had tight, impermeable apical junctions consistent with a distal origin. By contrast, cysts with a sodium concentration not greatly different from that found in plasma were found to have loose, permeable apical junctions consistent with a proximal origin.

Although these studies have provided important indirect information regarding the origin and possible function of cyst epithelium in adult polycystic kidney disease, no studies have directly measured transport function of such cysts. For this purpose, cyst epithelia from a human polycystic kidney were studied in vitro using Ussing chamber techniques. These studies demonstrate directly the existence of active transport in cysts that exhibit substantial $\mathrm{Na}^{+}$and $\mathrm{K}^{+}$gradients in relationship to plasma.

\section{Methods}

Cysts obtained from a human polycystic kidney removed electively in preparation for renal transplantation were studied. At surgery, the kidney was removed within $\sim 10 \mathrm{~min}$ after clamping of the renal vascular pedicle. All of the cysts were from one kidney. Surface cysts were identified, cyst fluid was aspirated, and the cyst wall dissected free and rinsed with oxygenated, bicarbonate Ringer. Cysts were then mounted in $1.13-\mathrm{cm}^{2}$ lucite hemichambers for the determination of flux and electrical parameters.

Although chamber techniques have been previously reported in detail (9), they will be briefly summarized. Ringer solution was bubbled with 95\% $\mathrm{O}_{2} / 5 \% \mathrm{CO}_{2}$ and had the following composition (in millimoles): $\mathrm{NaCl}, 112 ; \mathrm{KCl}, 5 ; \mathrm{CaCl}_{2}, 1.25 ; \mathrm{MgCl}_{2}, 1.1 ; \mathrm{Na}_{2} \mathrm{HPO}_{4}, 2.4 ; \mathrm{NaH}_{2} \mathrm{PO}_{4}$, $0.6 ; \mathrm{NaHCO}_{3}, 25$; and glucose, 10. Solutions were stirred and oxygenated using water-jacketed, gas-lift recirculators maintained at $37^{\circ} \mathrm{C}$. Potential difference (PD) ${ }^{1}$ was measured using calomel half-cells that were connected to the chambers via $4 \%$ agar $\mathrm{NaCl}$ bridges. Current was passed via $\mathrm{Ag}-\mathrm{AgCl}$ electrodes. Cysts were continuously short-circuited via automatic voltage clamps (B. C. I. Buck, Franklin, MA) except for brief periods during which the open-circuit PD was determined. The shortcircuit current $\left(\mathrm{I}_{\mathbf{x c}}\right)$ was corrected for fluid resistance by a compensating circuit built into the voltage clamp. Conductance $(G)$ was calculated from the $I_{s c}$ divided by the open-circuit PD.

Unidirectional fluxes of ${ }^{22} \mathrm{Na}$ and ${ }^{36} \mathrm{Cl}$ were determined simultaneously for each cyst epithelium. Approximately $1-2 \mu \mathrm{Ci}$ of both isotopes were added to the inside (mucosal) or outside (serosal) bath. Ionic flux $\left(\mathrm{J}_{\mathrm{i}}\right)$ from inside to outside has been designated as mucosa-to-serosa $\left(\mathrm{J}_{\mathrm{i}} \mathbf{M}-\right.$ S) flux, whereas flux from outside to inside has been designated as serosato-mucosa $\left(\mathrm{J}_{i} \mathrm{~S}-\mathrm{M}\right)$ flux. After an equilibration period of at least $20 \mathrm{~min}$, two 20-min flux periods were obtained, followed by the addition of amiloride to the mucosal bath and two additional 20-min flux periods. Amiloride (a generous gift from Merck, Sharp, \& Dohme, West Point, PA)

1. Abbreviations used in this paper: $\mathrm{G}$, conductance; $\mathrm{I}_{\boldsymbol{x}}$, short-circuit current; J, flux; M-S, mucosa-to-serosa; PD, potential difference; S-M, serosa-to-mucosa. 
was added in a small amount of $\mathrm{H}_{2} \mathrm{O}$ to achieve a final concentration of $10 \mu \mathrm{M}$.

Measurements taken during the two flux periods for each experimental condition were averaged. All results are expressed per $\mathrm{cm}^{2}$. Due to the small number of measurements, statistical analysis was not undertaken.

The plasma electrolytes, blood urea nitrogen, and creatinine were determined by the clinical chemistry laboratory at New England Medical Center using standard laboratory techniques and were obtained by chart review. The concentrations of sodium and potassium in cyst fluid were determined by flame photometry (KLiNa Flame, Beckman Instruments Inc., Fullerton, CA) and the cyst fluid creatinine using a Technicon autoanalyzer (Technicon Instruments Corp., Tarrytown, NY). This protocol was approved by the Human Investigation Review Committee of TuftsNew England Medical Center.

\section{Results}

Characteristics of the patient. The patient was a 48-yr-old male with polycystic kidney disease that was diagnosed at the age of 28. His clinical course was typical and marked by recurrent episodes of cyst infection, hematuria, and the development of hypertension. Chronic hemodialysis was initiated $1 \mathrm{yr}$ before nephrectomy. Neither the patient's parents or four female sibs had evidence of renal disease, although definitive investigation was not performed. Laboratory data obtained $24 \mathrm{~h}$ before surgery are as follows: creatinine, $12.1 \mathrm{mg} / \mathrm{dl}$, blood urea nitrogen, 75 $\mathrm{mg} / \mathrm{dl}, \mathrm{Na}^{+}, 146 \mathrm{meq} / \mathrm{liter}, \mathrm{Cl}^{-}, 109 \mathrm{meq} / \mathrm{liter}, \mathrm{K}^{+}, 5.4 \mathrm{meq} /$ liter, and total $\mathrm{CO}_{2}, 23 \mathrm{meq} / \mathrm{liter}$. The patient was hemodialyzed once between the time of blood drawing and nephrectomy.

Cyst fluid composition. The gross appearance of the cyst fluid did not correlate with any of the other parameters (see Table I). Based on the sodium concentration, two populations of cysts can be described. Cysts with a substantial gradient between cyst fluid and plasma sodium were designated gradient cysts (cysts 4 and 5), whereas cysts with a similar cyst fluid and plasma sodium were designated nongradient cysts (cysts 1-3). This terminology will be used throughout, as it is simple and requires no assumptions about cyst origin. There was no apparent relationship between cyst fluid creatinine concentration and sodium gradient in contrast to previous studies (8). However, plasma creatinine in this patient varied in the $24 \mathrm{~h}$ before surgery on account of hemodialysis.

Transport characteristics. The electrical parameters of the

Table I. Cyst Fluid Composition

\begin{tabular}{llllc}
\hline Cyst & $\begin{array}{l}\text { Fluid } \\
\text { appearance }\end{array}$ & $\mathrm{Na}^{+}$ & $\mathrm{K}^{+}$ & Creatinine \\
\hline & & meq/liter & meq/liter & $m g / d l$ \\
1 & Chocolate & 139 & 4 & 6.7 \\
2 & Clear & 141 & 5 & 8.0 \\
3 & Red & 138 & 5 & 10.0 \\
4 & Purulent & 2 & 13 & 6.7 \\
5 & Brown & 5 & 15 & 4.9 \\
\hline
\end{tabular}

The gross appearance and composition of cyst fluid obtained at the time of nephrectomy is indicated above. This fluid was obtained from the same cysts used for transport studies. Cysts 1-3 have $\mathrm{Na}^{+}$and $\mathrm{K}^{+}$ not greatly different from plasma; cysts 4 and 5 demonstrate significant $\mathrm{Na}^{+}$and $\mathrm{K}^{+}$gradients, suggestive of active transport.
Table II. Transport Characteristics of Cysts In Vitro

\begin{tabular}{|c|c|c|c|c|c|c|c|}
\hline Cyst & PD & $\mathbf{I}_{\boldsymbol{\infty}}$ & G & $\mathrm{J}_{\mathrm{Ne}_{0} \mathrm{M}-\mathrm{S}}$ & $\mathrm{J}_{\mathrm{N}_{0}} \mathrm{~S}-\mathrm{M}$ & $\mathrm{J}_{\mathrm{a}} \mathrm{M}-\mathrm{S}$ & $\mathrm{J}_{\mathrm{G}} \mathrm{S}-\mathrm{M}$ \\
\hline & $m V$ & $\mu e q \cdot h^{-1} \cdot \mathrm{cm}^{-2}$ & $\mathrm{~ms} / \mathrm{cm}^{2}$ & \multicolumn{4}{|c|}{ All fluxes in $\mu e q \cdot h^{-1} \cdot \mathrm{cm}^{-2}$} \\
\hline 1 & 0.6 & 0.4 & 23.7 & 15.5 & - & 17.1 & - \\
\hline 2 & -0.0 & -0.1 & 53.6 & 67.6 & - & 77.2 & - \\
\hline 3 & -0.4 & -0.3 & 20.5 & 14.5 & - & 16.3 & - \\
\hline 4 & 2.6 & 0.6 & 6.5 & - & 3.9 & - & 4.8 \\
\hline 5 & 7.2 & 0.8 & 3.1 & 3.9 & - & 2.5 & - \\
\hline
\end{tabular}

Data represent the mean electrical parameters and flux measurements for the first two 20-min flux periods. Due to the small number of cysts and the lack of bidirectional flux measurements, it was not possible to calculate net fluxes. Cysts previously designated as having a $\mathrm{Na}^{+}$gradient (4 and 5) demonstrate greater PD and $I_{s c}$, and lower $G$ and flux values than nongradient cysts (1-3).

individual cysts are indicated in Table II. A clear separation between gradient and nongradient cysts is evident. Nongradient cysts (1-3) demonstrate low values for PD and $I_{s c}$, but have a high $\mathrm{G}$. Note, however, that $\mathrm{G}$ for cyst 2 is substantially higher than that of any of the other cysts. Gradient cysts (4 and 5), by contrast, have elevated PD and $I_{s c}$ with a much lower $G$. The presence of the elevated PD and $\mathrm{I}_{\mathrm{sc}}$ of gradient cysts is consistent with the presence of active transport, but does not provide any information about the type of transport.

Unidirectional sodium chloride fluxes for the first $40 \mathrm{~min}$ are also displayed in Table II. All fluxes are in $\mu \mathrm{eq} \cdot \mathrm{h}^{-1} \cdot \mathrm{cm}^{-2}$. Due to the small number of cysts and the absence of bidirectional flux measurements, it was not possible to calculate net fluxes. Several important findings will be highlighted, however. Note that, in general, sodium and chloride fluxes were greater in nongradient than in gradient cysts. Except for cyst 2, nongradient cyst sodium chloride fluxes were in a range similar to that found in a leaky epithelium, such as small intestine (10), whereas values noted for gradient cysts were similar to those found in tight epithelia, such as large intestine and toad urinary bladder $(11,12)$.

To obtain additional information about the nature of ion transport by these cysts, the diuretic agent amiloride was used. Amiloride, at a concentration of $10 \mu \mathrm{M}$, specifically but reversibly inhibits conductive sodium entry, an effect localized to the mucosal or luminal membrane (13). This form of sodium transport is found in the distal nephron (14), but is also seen in other epithelia, such as large intestine $(9,11)$ and toad urinary bladder (12). Inhibition of conductive sodium transport by this agent results in an equivalent reduction in $I_{s c}$ under voltage-clamped conditions. The effect of mucosal amiloride on PD and $I_{s c}$ of gradient cysts is demonstrated in Fig. 1. Addition of $10 \mu \mathrm{M}$ amiloride to the mucosal membrane resulted in a dramatic reduction in the PD and $I_{s c}$, which was partially reversible on washout. Values of PD and $I_{s c}$ remained stable or improved for an additional $2.5 \mathrm{~h}$, at which point repeat application of $10 \mu \mathrm{M}$ amiloride to the mucosal surface again resulted in a rapid reduction of $P D$ and $I_{s c}$. Although $J_{\mathrm{Na}} \mathrm{M}-\mathrm{S}$ of cyst 5 decreased after the initial addition of amiloride, the reduction in $\mathbf{J}_{\mathrm{Na}} \mathbf{M}-\mathbf{S}$ (1.9 $\left.\mu \mathrm{eq} \cdot \mathrm{h}^{-1} \cdot \mathrm{cm}^{-2}\right)$ exceeded the reduction in $\mathrm{I}_{\mathrm{sc}}(0.9$ $\mu \mathrm{eq} \cdot \mathrm{h}^{-1} \cdot \mathrm{cm}^{-2}$ ). The $\mathrm{I}_{\mathrm{sc}}$ and PD of nongradient cysts were not affected by amiloride (data not shown). These results indicate that gradient cysts demonstrate in vitro conductive, amiloride- 

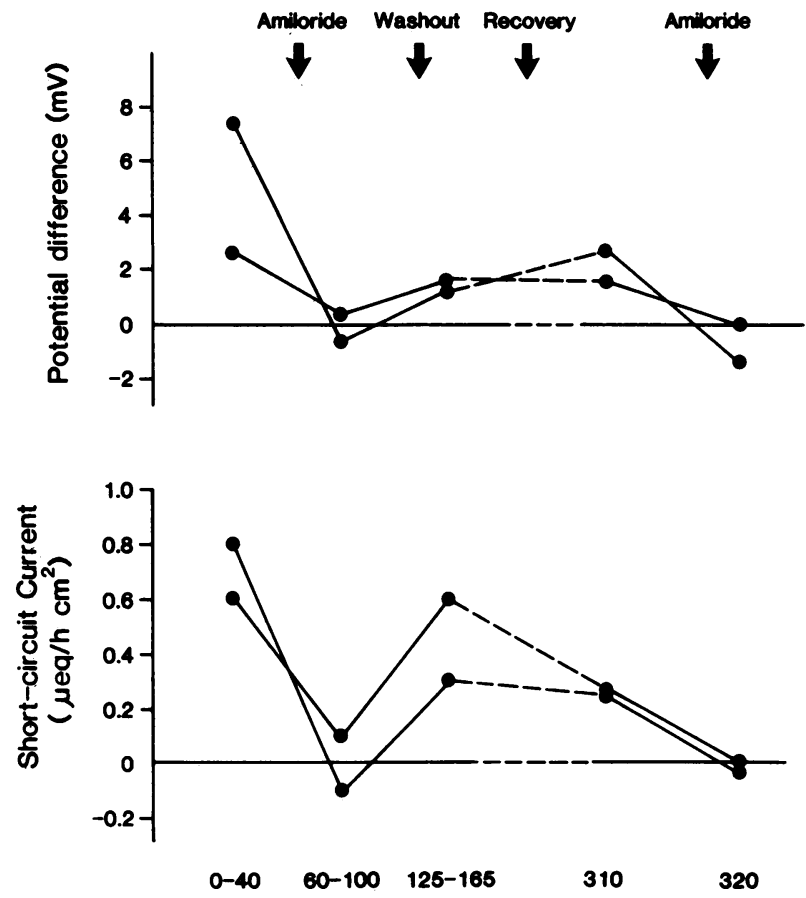

Time (minutes)

Figure 1. Response of gradient cysts to amiloride. PD and $\mathrm{I}_{\mathbf{x}}$ of gradient cysts (4 and 5) are indicated in the top and bottom panels, respectively. Addition of amiloride to the serosal bath (cyst 5) had no effect. Amiloride $(10 \mu \mathrm{M})$ was then added to the mucosal bath and PD and $I_{x c}$ rapidly decreased. After amiloride was washed out, both parameters partially recovered. These remained stable or increased for several hours, at which point repeat application of $10 \mu \mathrm{M}$ amiloride to the mucosal bath caused a similar rapid reduction of $P D$ and $I_{s c}$. These findings document the presence of conductive $\mathrm{Na}^{+}$transport in gradient cysts, confirming the distal origin.

sensitive sodium transport, as would be expected if cysts arose from a segment of distal nephron.

Although the transport function of gradient cysts is suggestive of distal nephron function, one must be cautious in ascribing proximal nephron function to nongradient cysts. When one considers the transport characteristics of cyst 2, which included a very high $G$, very low $P D$ and $I_{s c}$, and very large sodium chloride fluxes, this indicates the likely absence of any epithelial function. Electron microscopic examination of this cyst (not shown) confirmed the complete absence of epithelial cells.

\section{Discussion}

Although long suspected on the basis of indirect evidence derived from studies of cyst fluid composition and cyst morphology, this study provides the first direct evidence for active transport by cysts from human polycystic kidney. Cysts that maintain a steep sodium gradient in vivo (gradient cysts) display active transport in vitro. This transport is manifested by amiloride-sensitive $I_{s c}$ and PD, typical of conductive or electrogenic sodium transport observed in distal nephron and related epithelial models.

The finding of only partial reversibility of the amiloride effect on washout should not be interpreted as indicating lack of specificity. It is indeed remarkable that these cysts functioned at all.
The two gradient cysts, for example, contained grossly purulent or brownish, hemorrhagic fluid, and were ischemic for $\sim 10-20$ min before mounting in oxygenated Ringer. Despite the trauma of handling, exposure to amiloride, and washout, both cysts maintained an easily measured $P D$ and $I_{s c}$ for at least $5 \mathrm{~h}$ after mounting.

Cysts that do not maintain a sodium gradient in vivo (nongradient cysts) appear to segregate into at least two categories: cysts with function similar to that of other loose epithelia (i.e., proximal nephron), and apparently damaged or nonfunctional cysts. The latter may have resulted from trauma (infection, hemorrhage, elevated pressure), or because the cyst originated from nonepithelial elements such as fibroblasts or glomerulus. It is not possible to make firm conclusions regarding the transport function of nongradient cysts on the basis of the small numbers reported in this study.

It is important to recognize that development of a sodium gradient in a cyst is dependent on both the presence of active transport and maintenance of a sufficiently low permeability so as to prevent dissipation of the gradient. In the absence of additional direct measurements of ion transport in nongradient cysts, further functional classification is not possible. It may occur, for example, that a nongradient cyst originated from the distal nephron but was damaged, such that an ion gradient could not be maintained. This cyst could only be identified as distal by the demonstration of the presence of conductive $\mathrm{Na}^{+}$channels or other characteristics of the distal nephron. For this reason, it is proposed that the terms nongradient and gradient be used to describe cysts, based on the $\mathrm{Na}^{+}$concentration instead of proximal or distal, as the proposed terminology requires no assumptions about the nephron segment of origin.

In summary, cysts from human polycystic kidney with low cyst fluid $\mathrm{Na}^{+}$manifest active transport when studied in vitro. Cysts with high $\mathrm{Na}^{+}$either have characteristics of proximal nephron or appear to be nonfunctional. Although additional studies are required to more fully describe transport characteristics of nongradient cysts, gradient cysts clearly manifest amiloride-sensitive $I_{s c}$ and $P D$, which strongly suggest their origin from distal nephron.

\section{Acknowledgments}

The author thanks Drs. H. Bush and D. H. Mitcheson for permission to study their patient and for assistance at the time of surgery. The author also gratefully acknowledges the technical assistance of S. Jeffress, C. A. Johns, M. L. McLaughlin, and E. S. Packman, and the excellent typing of the manuscript by $\mathrm{P}$. Ardolino. Electron micrographs were skillfully prepared by W. Woods under the supervision of A. A. Ucci.

This study was supported in part by the Charlton Fund of Tufts University School of Medicine.

\section{References}

1. Grantham, J. J. 1983. Polycystic kidney disease: a predominance of giant nephrons. Am. J. Physiol. 244(Renal Fluid Electrolyte Physiol. 13):F3-F10.

2. Grantham, J. J. 1984. Polycystic kidney disease hereditary and acquired. Kidney. 17:19-23.

3. Baert, L. 1978. Hereditary polycystic kidney disease (adult form): a microdissection study of two cases at an early stage of the disease. Kidney Int. 13:519-525.

4. Lambert, P. P. 1947. Polycystic disease of the kidney. Arch. Pathol. 44:34-58. 
5. Potter, E. L. 1972. Normal and Abnormal Development of the Kidney. Year Book Medical Publishers, Inc. p. 3, Chicago.

6. Gardner, K. D., Jr. 1969. Composition of fluid in twelve cysts of a polycystic kidney. N. Engl. J. Med. 281:985-988.

7. Cuppage, F. E., R. A. Huseman, A. Chapman, and J. J. Grantham. 1980. Ultrastructure and function of cysts from human adult polycystic kidneys. Kidney Int. 17:373-381.

8. Huseman, R., A. Grady, D. Welling, and J. Grantham. 1980. Macropuncture study of polycystic disease in adult human kidneys. Kidney Int. 18:375-385.

9. Perrone, R. D., and S. L. Jenks. 1984. Suppression of coupled $\mathrm{Na}-\mathrm{Cl}$ absorption by aldosterone and dexamethasone in rat distal colon in vitro. Am. J. Physiol. 246(Renal Fluid Electrolyte Physiol. 15):F785F793.
10. Nellans, H. N., R. A. Frizzell, and S. G. Schultz. 1975. Effect of acetazolamide on sodium and chloride transport by in vitro rabbit ileum. Am. J. Physiol. 228:1808-1814.

11. Turnheim, K., R. A. Frizzell, and S. G. Schultz. 1977. Effect of anions on amiloride-sensitive, active sodium transport across rabbit colon, in vitro. J. Membr. Biol. 37:63-84.

12. MacKnight, A. D. C., D. R. DiBona, and A. Leaf. 1980. Sodium transport across toad urinary bladder: a model "tight" epithelium. Physiol. Rev. 60:615-715.

13. Benos, D. J. 1982. Amiloride: a molecular probe of sodium transport in tissues and cells. Am. J. Physiol. 242(Cell Physiol. 11):C131C145.

14. Jacobson, H. R. 1981. Functional segmentation of the mammalian nephron. Am. J. Physiol. 241(Renal Fluid Electrolyte Physiol. 10):F203F218. 